\title{
Transanal Endoscopic Microsurgery - State of the Art
}

\author{
Pablo Palma ${ }^{1}$ and Karoline Horisberger ${ }^{2}$ \\ ${ }^{1}$ Division of Colon \& Rectal Surgery, University Hospital HUVN Granada, \\ 2Department of Surgery, University Hospital Mannheim, \\ ${ }^{1}$ Spain \\ ${ }^{2}$ Germany
}

\section{Introduction}

The first description of surgery for rectal cancer was reported by the French surgeon Lisfranc who described a total of nine patients operated trough a perineal-transanal approach (Lisfranc, 1830). Although more recently gaining popularity, transanal techniques have long been used for the treatment of rectal diseases and were promoted by the work of Sir Alan Parks at St. Marks Hospital in London in the 1950s (Parks, 1970). This conventional surgical approach is well suited for the management of selected low rectal lesions; on the contrary, removal of lesions in the middle and upper rectum are less feasible due to the limited accessibility and inadequate exposure afforded by standard instrumentation. For these reasons, those more proximal lesions have historically been tackled by more radical surgical approaches, like abdominal low anterior, abdominoperineal, transsacral, and transsphincteric resections.

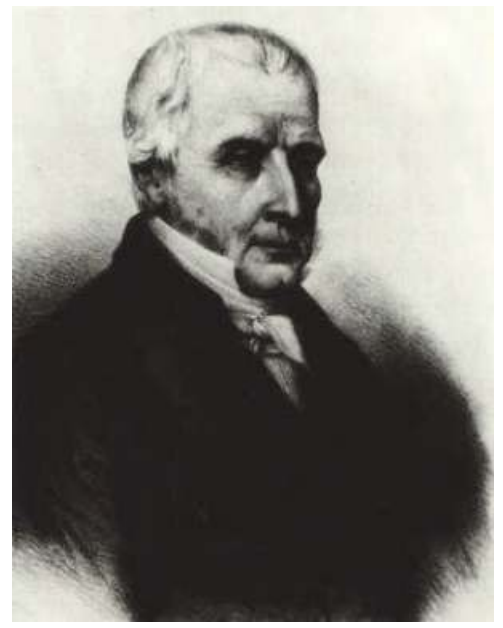

\section{MÉMOIRES}

De

L'ACADÉMIE ROYALE,DE MÉDECINE.

TOME TROISUk̀me.

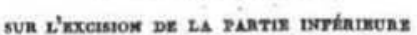

DU RECTUM

DEVEAUE CARCAYOMTEUSE.

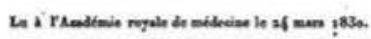

Par J. LISFRANC, chirurgies on chef de Ibopital de la Pitid, membre

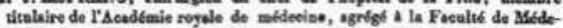
cine de Paris, profecueser de clinique exterse st de midecibe opératoire, ete.

Fig. 1. J. Lisfranc's description of surgery for rectal cancer. 
Transanal endoscopic microsurgery (TEM) came into practice in Germany, in the early 1980s through the collaboration of the German surgeon Gerhard Buess and the Medical Company Richard Wolf (Buess et al., 1984). Its initial indication was to remove large rectal polyps beyond the reach of standard transanal excision. TEM is a technique for the performance of local excision, by the way of a binocular, magnified operating system. This equipment involves an operating proctoscope, insufflation, and magnified stereoscopic vision. In fact, the three-dimensional amplification, magnified stereoscopic view and lighting within the rectal lumen, allow excellent vision of the operative field, enabling the surgeon to perform an extremely precise excision of rectal lesions, including a full-thickness excision. It has evolved into a valuable, state-of-the-art technology equaling any other technique in terms of reliably positive patient outcome. Its application has expanded beyond the excision of colonoscopically unresectable polyps to the removal of select, early rectal cancers, independent of prior adjuvant chemoradiation therapy. Further fields of use include the treatment of anastomotic strictures, and repair of proximal, complex rectal fistulae. TEM allows greater flexibility and options for the operating surgeon. In addition to extending the surgeon's reach up to the distal sigmoid colon, the four ports of access allow for concomitant use of an illuminated camera, forceps, cautery, suction as well as the freedom to apply common laparoscopic techniques such as suturing and different energy sources.

TEM has been found useful in the treatment of a broad variety of disease processes, both benign and malignant. Though many indications have been described, including excision of carcinoids or even retrorectal tumors, the most common use of TEM remains the resection of colonoscopically unresectable rectal adenomas and carefully selected rectal cancers. It should be stressed that even though TEM extends the reach of conventional transanal resections, it should not lead to any deviation from the established stringent indications for resection, especially in regard to rectal cancer (Palma et al, 2004).

Due to the limited visibility and access inherent to traditional transanal retractors, use of the latter has been restricted to the resection of low rectal polyps and suitably located early cancers. The TEM technique grants access to the entire rectal cavity, facilitating the reach of lesions with their proximal margin located as far as $20 \mathrm{~cm}$ from the anal verge. Some of the limitations of TEM are due to the surgeon's personal skills and experience. The conditions treated by TEM, namely, colonoscopically unresectable rectal polyps and early cancers, are far less common in terms of incidence and epidemiology, than those treated by abdominal laparoscopic operations, thus limiting any single surgeon's or institution's volume and operative experience.

Contemporarily several factors have induced a new interest for TEM among practitioners, predominantly due to surging controversy about increased local recurrence rates following standard transanal resection of favorable early stage rectal cancers. TEM bears some advantage over standard transanal excision of neoplasms, including better visualisation of the surgical field and tumor margins. Inflicting fewer traumas, the probability of tumor fragmentation and dissemination diminishes, while additionally enabling resection of the potentially infiltrated mesorectum. As a matter of fact, more and more surgeons are being trained with advanced endoscopic skills. Synergistically these skills make handling the TEM equipment more feasible and surgeons face a less steep learning curve, generally promoting the use of the procedure.

Also, the use of TEM may not be restricted to the anal cavity, but serve as a gateway to the peritoneum for natural orifice transluminal endoscopic surgery (NOTES). Transrectal access to the peritoneum via TEM has the future potential to facilitate the removal of larger organs, 
maintenance of pneumoperitoneum, endoscopical visualisation of upper abdominal organs and secure suture closure of the proctotomy, by the application of larger, more versatile instruments.

\section{TEM Equipment}

\subsection{Articulated stabilising arm}

The proctoscope is aligned using an articulated arm, also known as the Martin arm, which is firmly attached to the operating table (figure 2). There are two ball joints which fully articulate and are locked into place with a single set screw. A bar at the one end of the articulated arm attaches to the rail on the operating table. At the opposite end the articulated arm attaches to the operating proctoscope.

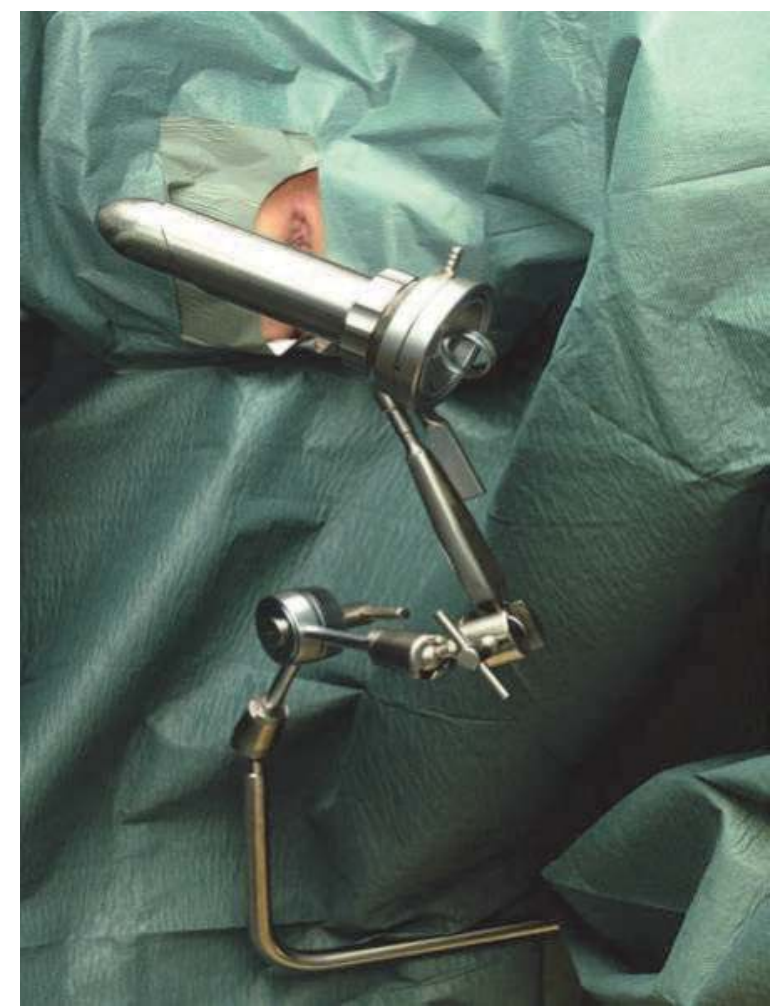

Fig. 2. Martin articulated arm.

\subsection{Operative proctoscopes}

The diameter of the operating proctoscope is $4 \mathrm{~cm}$, it is available in two different lengths, 10 and $20 \mathrm{~cm}$ and allows access throughout the rectum. A rotating collar on the handle locks the scope shaft, creating an airtight seal. The handle comes with a port, allowing the attachment of a hand-bulb insufflator or a tube for monitoring the $\mathrm{CO} 2$ pressure (figure 3). 


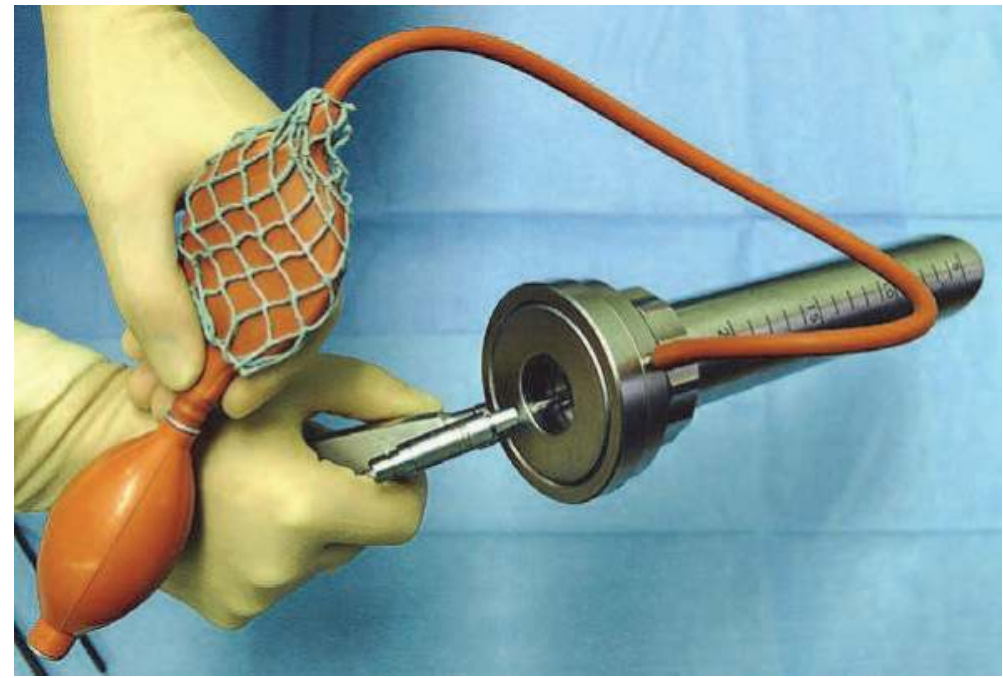

Fig. 3. TEM operating proctoscope $(20 \mathrm{~cm})$ with hand-bulb insufflator.

A faceplate is fitted to the handle and locked with an sealed lever. This faceplate has a port for the optics and three rubber caps for the long operating instruments (figure 4). These ports are able to maintain pneumorectum and are fitted with holes of varying size, to accommodate instruments of different diameters. The right-side operating port is slightly larger and thus requires a slightly larger cap. Flap valves in the snap-on multiport piece serve to help prevent gas leaks.

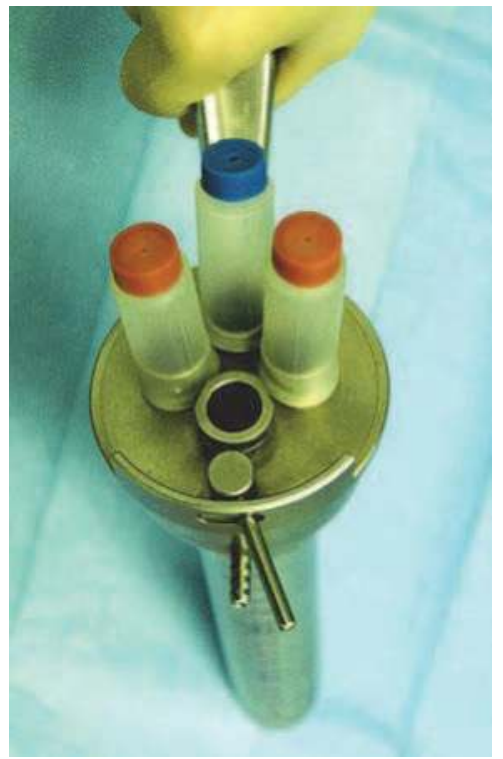

Fig. 4. TEM faceplate with four ports. 


\subsection{Optics}

A 10-mm stereoscope which provides a high-definition, three-dimensional view is used. The stereoscope's long, rigid shaft is inserted into the optic port on the faceplate and extends the entire length of the operating proctoscope.

A 40o, 5-mm scope is inserted into the stereoscope and connected to a camera, allowing a live feed from the rectal cavity to be displayed on a video monitor. The stereoscope also has two ports serving for water irrigation and $\mathrm{CO} 2$ insufflation (figure 5).

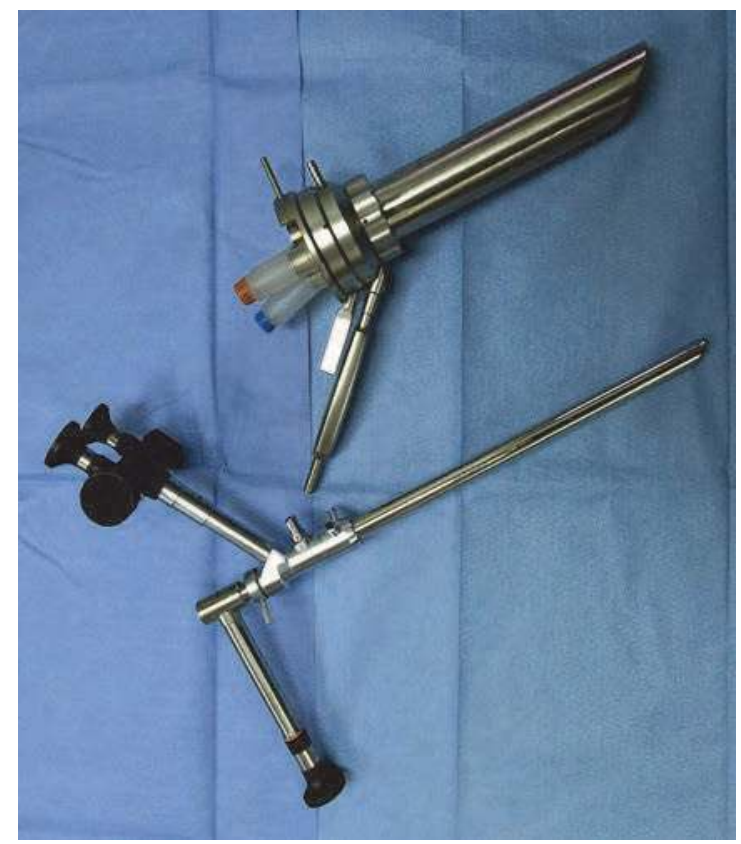

Fig. 5. TEM proctoscope (above) and $10 \mathrm{~mm}$ stereoscope (below), attached to a $5 \mathrm{~mm}$ scope for video viewing.

\subsection{TEM Instruments}

Long instruments are needed access the surgical field via the operating TEM proctoscopes (figure 6). The instruments include electrocautery, forceps, scissors, suction probe, clip applier, needle holder, and retractable needle.

There are two variants of forceps, either straight or angled. Both types are provided on instruments with tips facing either left or right. Each instrument may be electrified individually. Also the scissors are provided with the tip facing either left or right, and are mainly used for cutting sutures.

The suction probe is a, double-curved, rigid tube designed to be inserted through the proctoscope and sit on the side of the scope's channel, not to obstruct vision during the procedure.

The needle device has a retractable needle within the tip of the rigid tube and may be extended or retracted with a syringe type handle. The needle holders are available with either a straight or an angled tip. The angled tip provides a slightly wider arc when passing 
a needle. In addition the jaws are "self-righting", when the needle is grasped it will rotate into the proper orientation by itself. The needle can be locked into position with a rotating ratchet controlled by the surgeon's thumb. The lock is released by over-squeezing the handle, allowing the surgeon to safely handle the needle.

The clip applier is a unique instrument which crimps a small silver clip onto the suture. Replacing the need for knot tying, clips are placed at the beginning and the end of running suture.

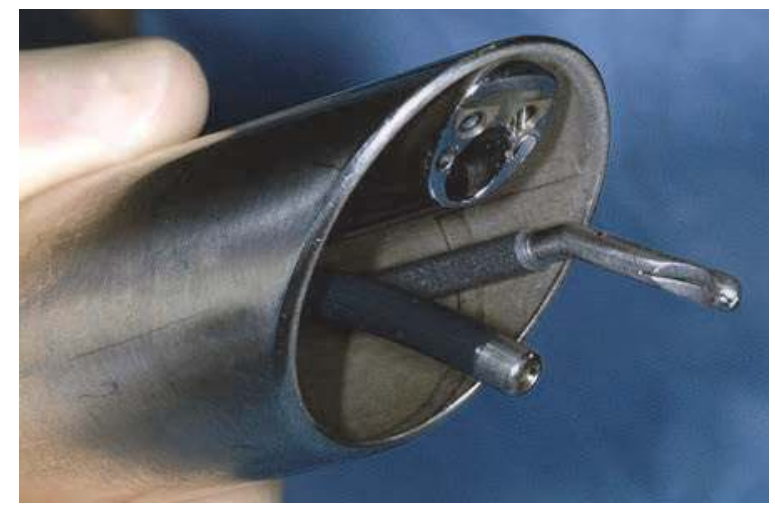

Fig. 6. TEM distal proctoscope opening showing the stereoscope together with forceps and suction probe.

\subsection{Specific TEM devices}

The specific device providing $\mathrm{CO} 2$ insufflation, water injection, and suction is stacked on a suitable portable cart (figure 7) as well as the video monitor, recorder and light source (figure 8). An electrocoagulation unit may be placed in the stack or a separate standard operating room unit may be employed.

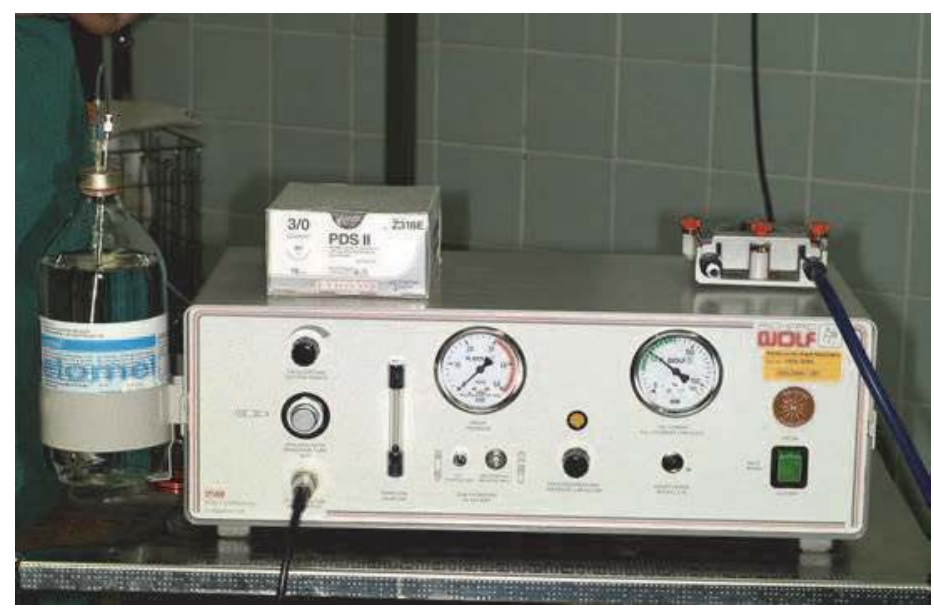

Fig. 7. Specific device for $\mathrm{CO} 2$ insufflation, water injection and suction. 
The insufflator injects CO2 via a port on the stereoscope's optic shaft. Lighting is supplied via a fiberoptic cord leading to a connector on the optic probe. Water irrigation may be engaged using a pedal. The water for irrigation flows through the stereoscope's shaft and is diverted across the optic tip, thus keeping the view clear.

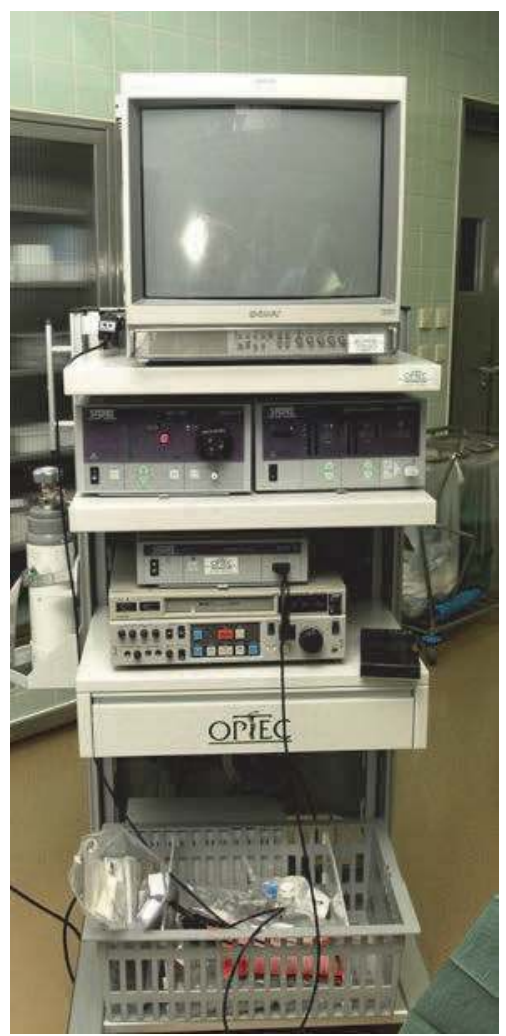

Fig. 8. The video monitor, recorder and light source are stacked on a portable cart.

\subsection{Surgical set-up}

Assembling the equipment can be time-consuming. The surgeon must position the patient in such way, that the tumor faces down directly towards the operating table; the choice of position is based upon prior examination in the office with a rigid proctoscope locating the tumor at both a specific level and a specific site on the circumference.

The patient may be placed in the lithotomy position, prone, or laterally; for a tumor that is almost circumferential the patient may need to be turned during the procedure. In our experience, the patient must be secured to the table with a bean bag, as the table may need to be rotated to bring the tumor into the center of the field. After positioning the bean bag, the articulated arm is attached to the operating table. The four tubes leaving the insufflation/suction devices must be connected properly.

Figure 9 shows the operation theatre setup with the patient in prone postion in order to reach the neoplasm, located on the anterior rectal wall. 


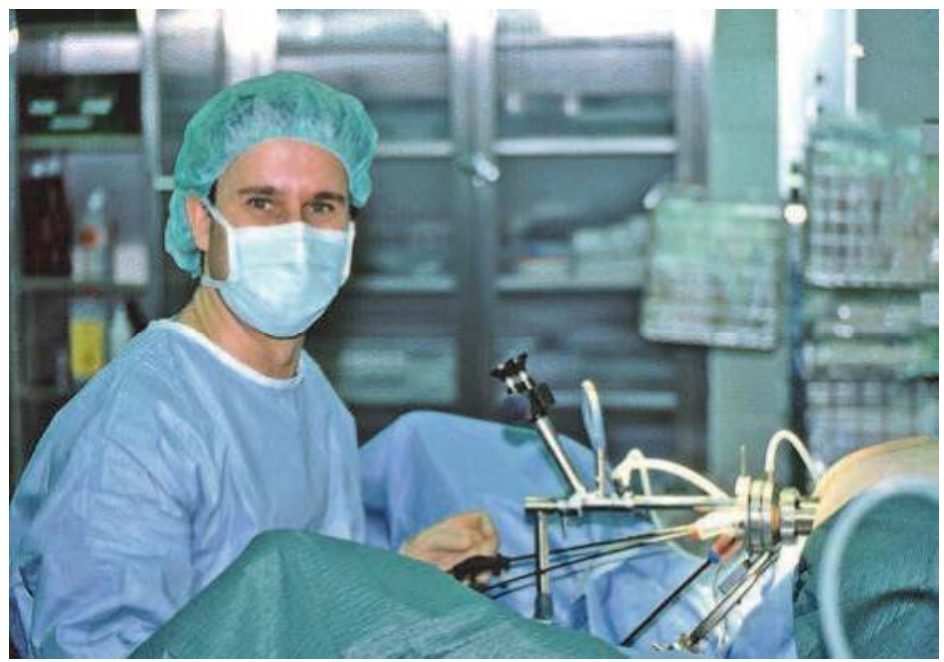

Fig. 9. Surgical setup with the patient in prone position

In conclusion, TEM requires specialized equipment and training. In addition to technical expertise, the dedicated TEM colorectal surgeon should be familiar with the necessary instruments and electronic devices. Expertise in troubleshooting is particularly helpful. There is, however, no substitute for a dedicated operating room team to ensure an efficient and successful TEM procedure.

\section{Surgical technique}

Preceding the procedure, bowel cleansing and prophylactic antibiosis have to be performed. In the actual procedure, two different operation techniques can be employed. Mucosectomy involves removing the mucosa, including the polyp from the inner circular layer of the muscularis; it represents a suitable technique for sessile adenomas located in the intraperitoneal portion of the rectum.

Full-thickness excision requires removal of all layers of the rectal wall, in the plane located just slightly superficial of the perirectal fatty tissue. This excision is performed for the majority of malignant lesions.

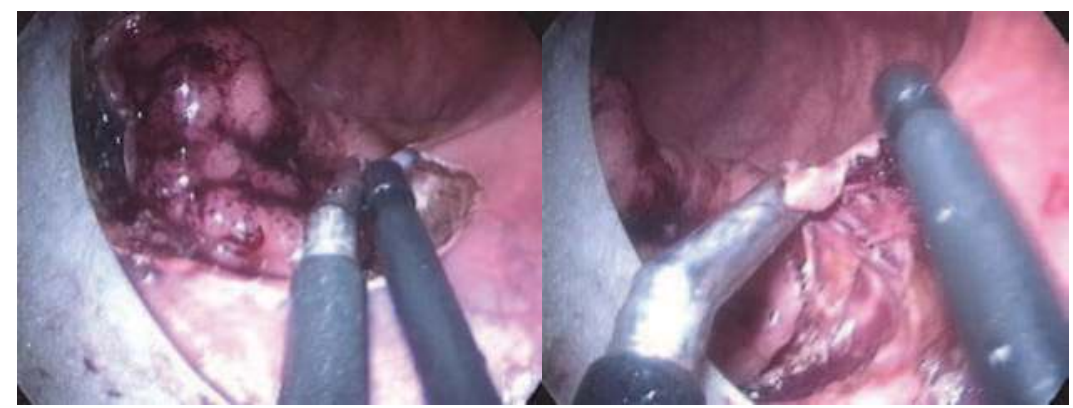

Fig. 10. Surgical dissection of an adenoma with two large TEM instruments. 
In cases of malignancy, it is imperative that the procedure includes not only a full-thickness excision but also a $1 \mathrm{~cm}$ safety margin of normal mucosa surrounding the lesion.

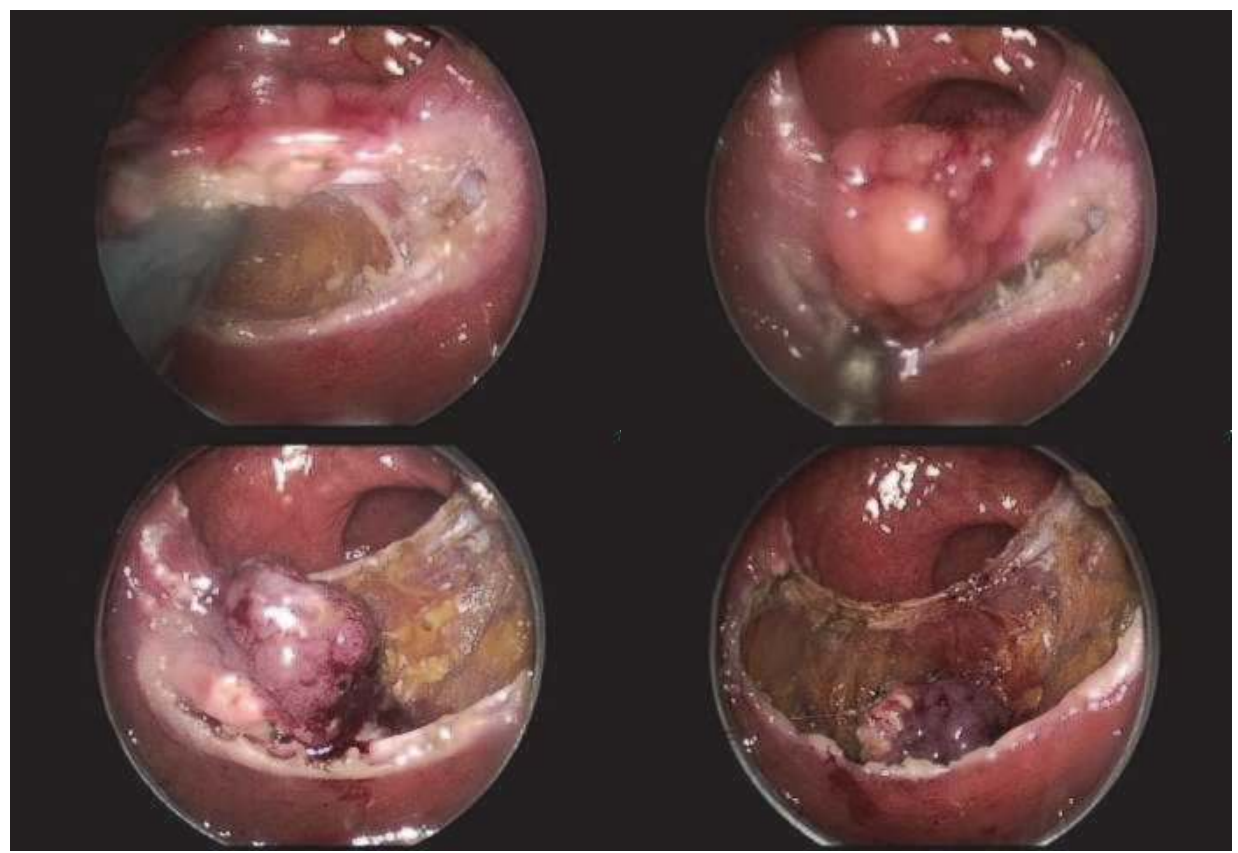

Fig. 11. TEM full-thickness dissection of rectal adenoma, showing the perirectal fatty tissue.

It is of crucial importance to correctly align the specimen on the cork board immediately after resection, to evaluate the safety margins before fixation with formalin. The proximal and distal margins of resection have to be identified to ensure correct histologic examination.

The rectal defect is closed by a running suture with a polydioxanone (3/0) monofilament and has to be performed transversely to prevent stenosis. The application of a silver clip at each end of the suture avoids the need for intraluminal knotting.

Alternatively, recent reports indicate the possibility to leave the defect open for secondary wound repair, especially in cases of partial-thickness excision.

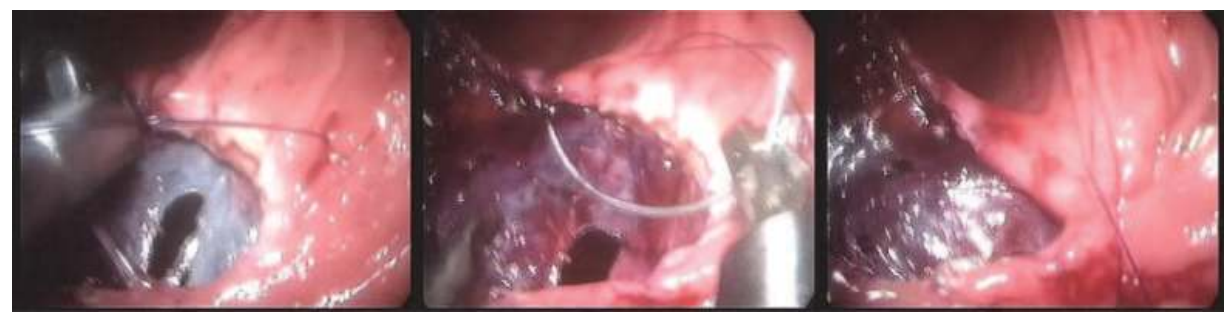

Fig. 12. Rectal wall defect closed by a running suture. Please note the peritoneal opening. Patient in the prone position. 
Following the excision of large masses, mobilization of the proximal and distal rectal wall will minimize tension on the suture line (figure 13). Approximating large defects with a single suture at the midpoint, facilitates the closure. Following this, the defect is closed from the peripheral margins to the center in running fashion. In our experience, modern instruments like the endo-stitch ${ }^{\mathrm{TM}}$ (Covidien) are well suited to perform the running suture.
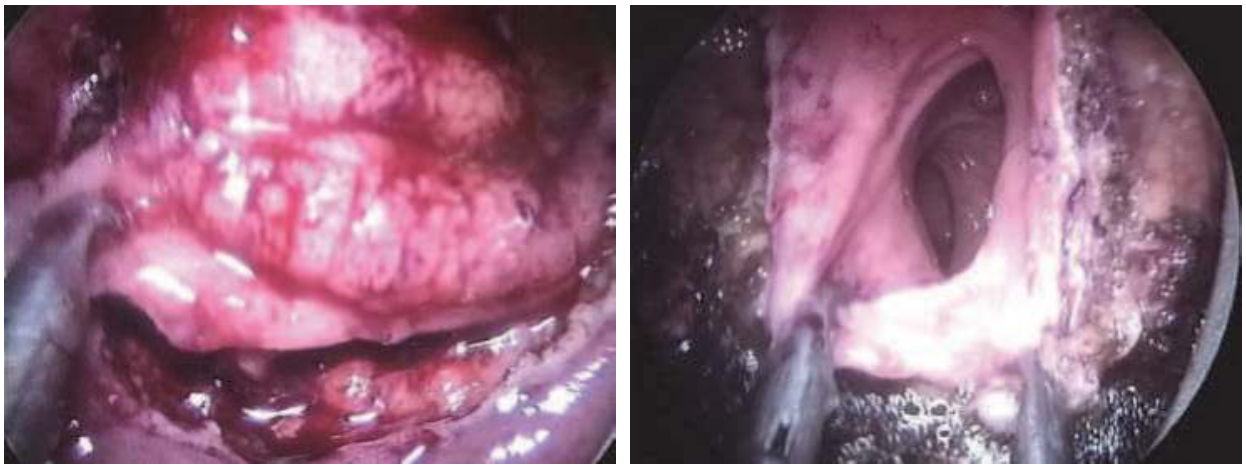

Fig. 13. Large rectal mass excision resulting in a $3 / 4$ defect to be closed.

\section{Patient selection and staging}

Resection of rectal and distal sigmoid adenomas is the most prominent indication for TEM. These benign lesions do not require mesorectal dissection, thus patients can be spared the morbidity of an unnecessary radical intervention. Smaller adenomas without evidence of high-grade dysplasia may be removed by partial-thickness (submucosal) excision. Larger adenomas or those with high-grade dysplasia are at high risk of containing invasive adenocarcinoma loci and should be excised full-thickness with a $10 \mathrm{~mm}$ resection margin.

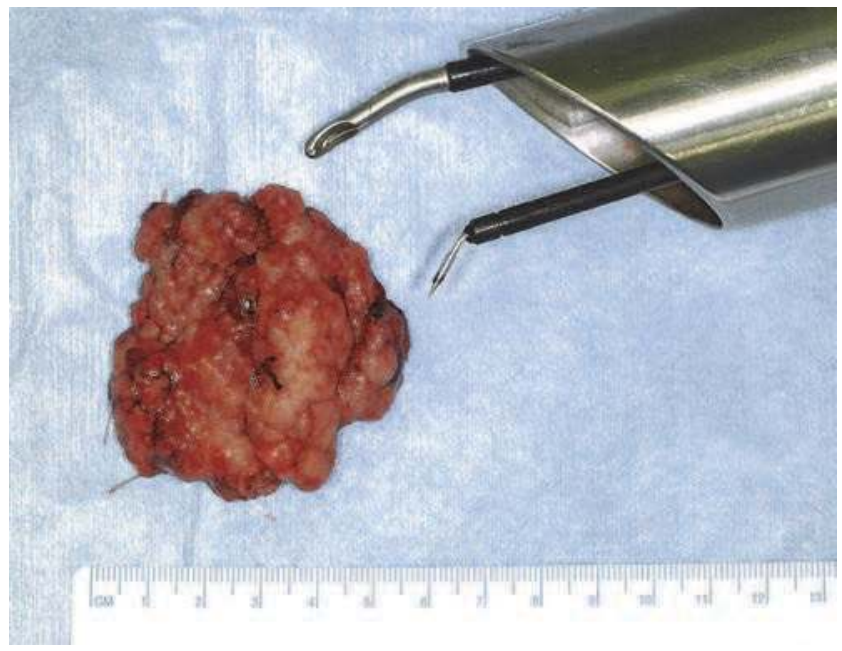

Fig. 14. Adenoma specimen after TEM excision. 
Resection of anterior rectal lesions requires special care. Full-thickness excision of the anterior and even lateral rectum carries the risk of unnoticed dissection into the vagina, urethra, or bladder. In this case, failure of adequate closure may lead to a rectourethral or rectovaginal fistula.

Intraperitoneal entry carries a risk of injuring intraabdominal structures, bacterial and potential cytologic contamination, as well as anastomotic leakage. Initially regarded as a complication, intraperitoneal excision with secure closure of the rectal defect has been performed with growing experience, without increased short-term morbidity (figure 12).

In case of a suspicious rectal polyp with unconfirmed malignancy in a patient unfit for or unwilling to undergo major abdominal surgery, TEM can be useful in resecting the entire lesion in one piece for complete histologic assessment. Salvage radical surgery, if indicated, can be performed thereafter without significantly increasing morbidity. TEM may also be useful as a palliative tool in patients with extensive metastatic disease or those medically unfit to withstand radical surgery. Neoadjuvant radiation therapy, when used in conjunction with resection, either aiming for cure or palliation, does not appear to increase complications following TEM.

Accuracy in the preoperative staging is mandatory to correctly select patients eligible for local excision. The routine use of endorectal ultrasound (figure 15), in combination with magnetic resonance imaging (MRI) has revolutionized our ability to perform accurate preoperative staging with respect to rectal wall penetration ( $\mathrm{T}$ stage) and regional lymph nodes (N stage) (figure 16).

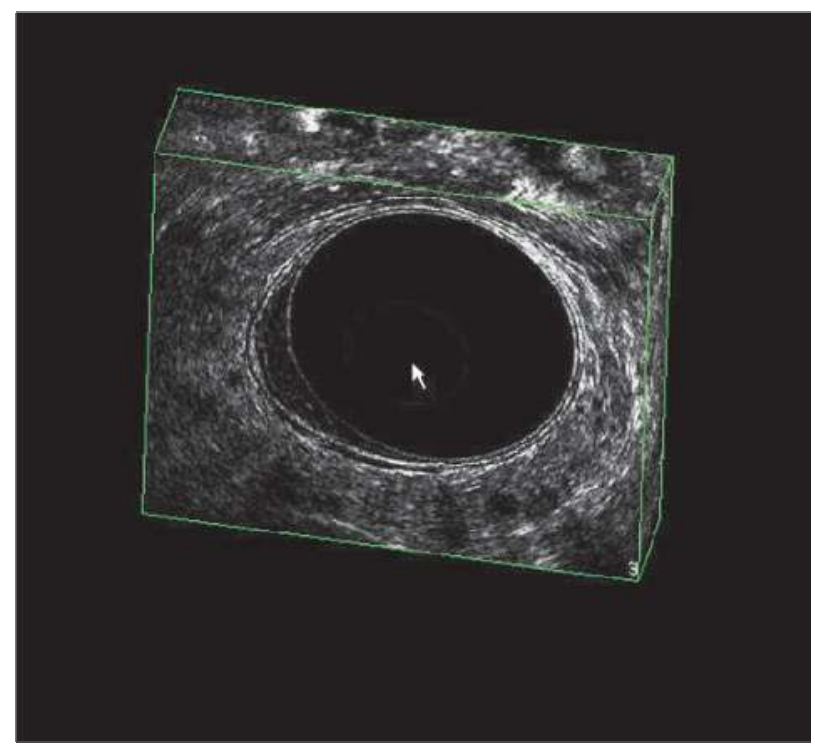

Fig. 15. 3D endorectal ultrsound showing a rectal mass without disruption of any of the rectal wall's layers.

Only patients with negative lymph nodes, a tumor limited to the wall of the rectum, presenting a diameter not exceeding $3 \mathrm{~cm}$ (in cases of malignancy), should be considered eligible for local excision. 


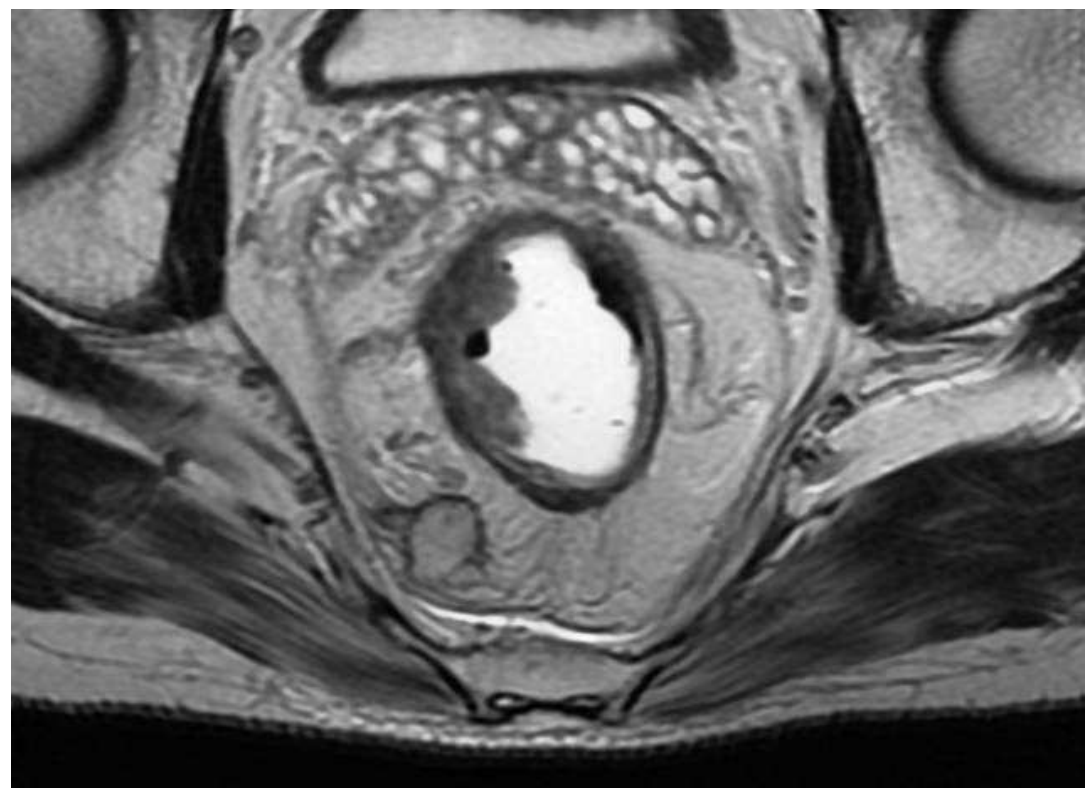

Fig. 16. Pelvic MRI T2 sequence, axial plane showing a rectal mass with a lymph node in the mesorectum.

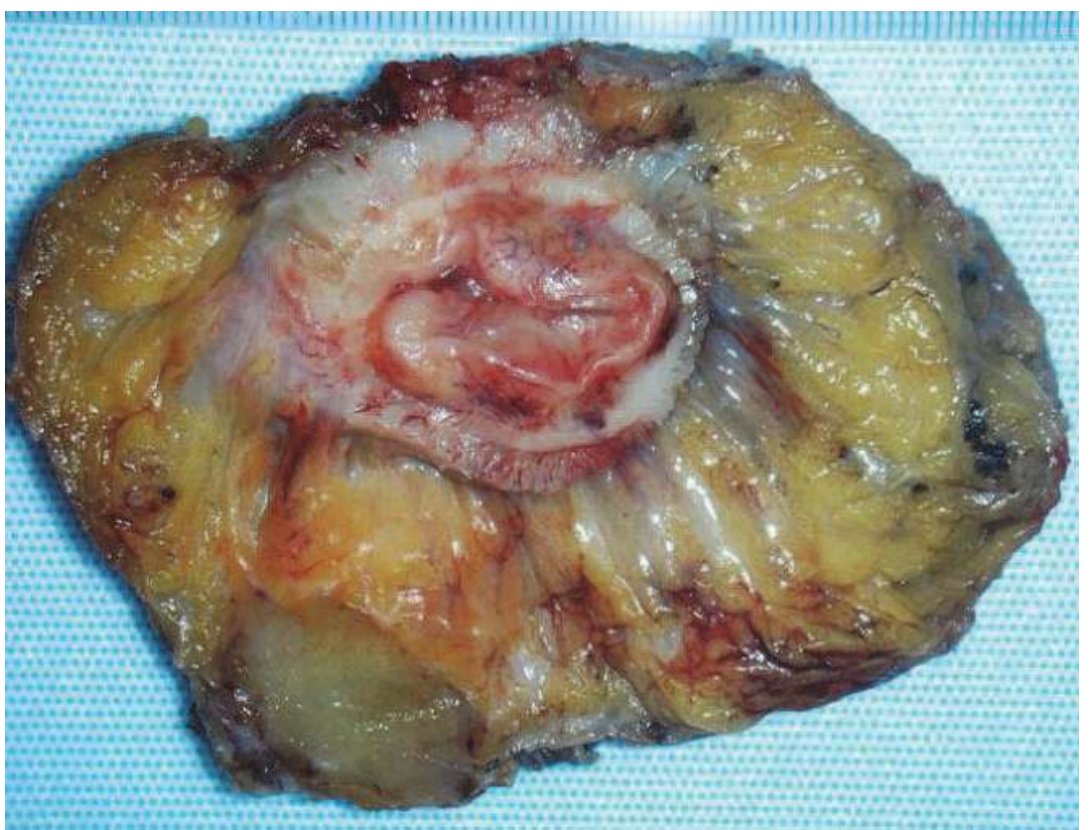

Fig. 17. Histopathological specimen obtained from the patient mentioned above, showing both the rectal mass and the mesorectal lymph node in contact with the mesorectal fascia. 
Preoperative staging workup includes:

- Digital rectal examination

- Colonoscopy

- Rectoscopy, to:

1. Perform biopsies

2. Measure the distance from the anal verge to the lesion

3. Evaluate the circumferential position of the tumor

4. Select an appropriate patient positioning for TEM approach

- Endorectal ultrasound

- Pelvic-MRI

- $\quad$ 18F-FDG PET-CT, specifically in our institution (figure 18).

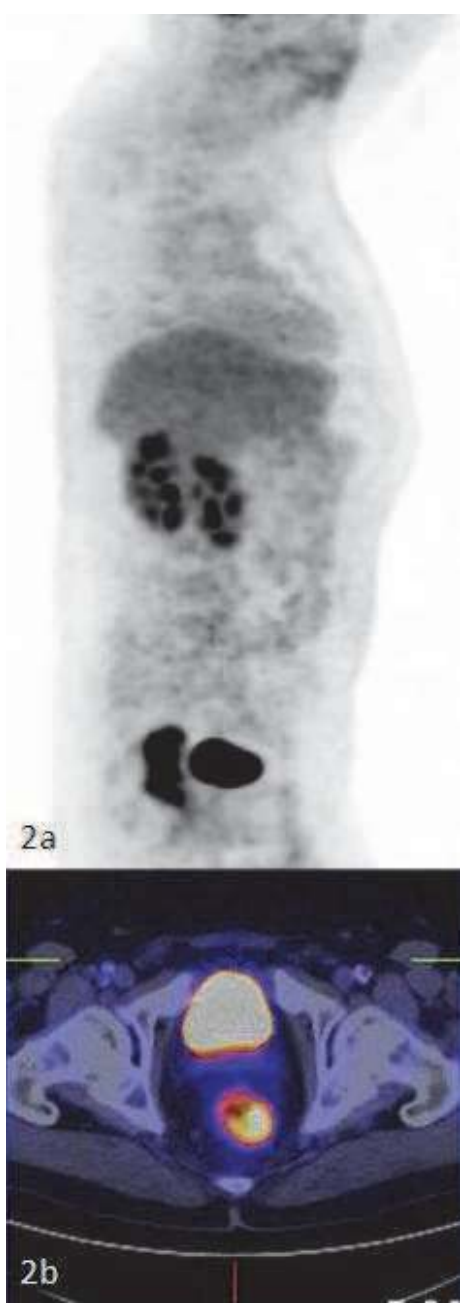

Fig. 18. 18F-FDG PET-CT showing pathologic intense glucose uptake due to rectal cancer. 
Each biopsy is examined by a dedicated pathologist to assess the tumor grade, as well as the lymphatic, neural, and blood vessel infiltration.

\section{Current indications and results}

Results from our experience and others are evaluated in the following chapter

\subsection{TEM for benign lesions}

Benign rectal tumors that are not suitable for snare diathermy excision are often amenable to removal via the transanal route, employing anal retractors and Parks's method (Parks, 1970). However, this method is limited to the lower third of the rectum. In addition, it may be difficult to visualize the margins of flat adenomas.

Conventional management of higher rectal lesions usually involves transabdominal procedures, posterior trans-sacral (Kraske), or sphincter-splitting (York-Mason) approaches.

However, these are major surgical procedures with associated complications and may be unsuitable and unnecessary if the purpose of the intervention is to resect benign lesions or low risk carcinomas.

With the development of TEM by G. Buess (Buess et al., 1984), it is now possible to carry out formal transanal resection by means of a rectoscope, which affords excellent access and vision in the entire rectum.

According to our experience, we recomend a full-thickness resection, to ensure an appropriate margin of safety. In addition, we found that this standard procedure is technically easier to perform than mucosectomy and that it decreases the risk of missing a small rectal cancer which may be located within the villous adenoma. Such 'intraephitelial neoplasia/dysplasia' or 'early invasion' has been reported in up to $31 \%$ of cases.

Although it is often difficult to ascertain the precise techniques (full-thickness or submucosal) used, the rates of complete excision at the time of operation and the exact follow up, large published series report a rate of recurrences in up to $27.3 \%$ after transanal excision of rectal adenomas (Sakamoto et al., 1991). In contrast the results reported using TEM show a recurrence rate between 3 and $7 \%$ with the $5.6 \%$ for the adenoma cases of our series pubished in 2004, being well in accordance with previous studies (Palma et al., 2004).

The overall morbidity rate for conventional transanal surgery in reported series varies from 0 to $14.5 \%$, compared with $6 \%$ reported in the largest series of a total of 318 adenomas treated by Mentges (Mentges et al., 1996). These results are in accordance with others TEMseries reporting morbidity of up to $4.5 \%$ in more than seven hundred patients and with our own experience $(7 \%)$.

It is of interest that postoperative bleeding is unusual with TEM, whereas it accounts for over half of the complications reported in other series (Sakamoto et al., 1991). Peritoneal entry, on the other hand, as assessed intra-operatively in 8 patient of our published experience (two of them with postoperative pneumoperitoneum), can be a significant source of morbidity with TEM. Presumably the excellent vision afforded by TEM allows more precise haemostasis, whereas the ability to excise high rectal lesions increases the likelihood of peritoneal entry, especially when the tumour is anterior, and thus more likely to be above the peritoneal reflection. In our experience, all perforations were recognized and managed by immediate endorectal suture (fig. 12).

Our results after initial 100 cases with TEM indicate that this technique is reproducible with suitable surgical training. 
Interestingly all three protective ileostomies in our series occurred within the first 20 cases indicating a learning curve, despite the fact that all surgeons received a special TEM training.

Regarding the effect of a prolonged anal dilatation with the $40 \mathrm{~mm}$ diameter TEM operative rectoscope, manometric studies indicate a decrease in anal sphincter tone ranging from $25 \%$ to $37 \%$ of pre-operative sphincter pressure, with recovery to clinical continence within 6-16 weeks (Herman et al., 2001). We observed postoperative transitory grade II incontinence in 65 of the 100 patients, with full recovery in $98 \%$ of the cases after 12 weeks. There is also evidence indicating a significantly increased risk of diminishing the anal resting pressure by procedures lasting more than two hours. Others found $21 \%$ disturbances of rectoanal coordination and rectal perception, depending on the extent and type of resection of the tumor. However, when making continence judgement, it would be necessary to consider the risk of incontinence by using the Parks retractor in conventional surgery, or after a low restorative rectal excision, if those were to be the alternative procedures.

In conclusion, TEM as a minimally invasive technique might be expected not only to benefit a small, specific population of patients in terms of morbidity but also to improve results in terms of completeness of excision and recurrence rates when compared to conventional transanal resection.

\subsection{TEM for early rectal cancer}

The standard treatment for early rectal cancer has been major surgery by anterior or abdominoperineal resection. After the introduction of total mesorectal excision, results regarding recurrence and survival rates have improved dramatically (figure 19). However, mortality, morbidity, and functional disturbances after major surgery are considerable. Perioperative mortality rates are usually 2 to 3 percent and overall morbidity 20 to 30 percent. Furthermore, anorectal, bladder, and sexual function may be compromised.

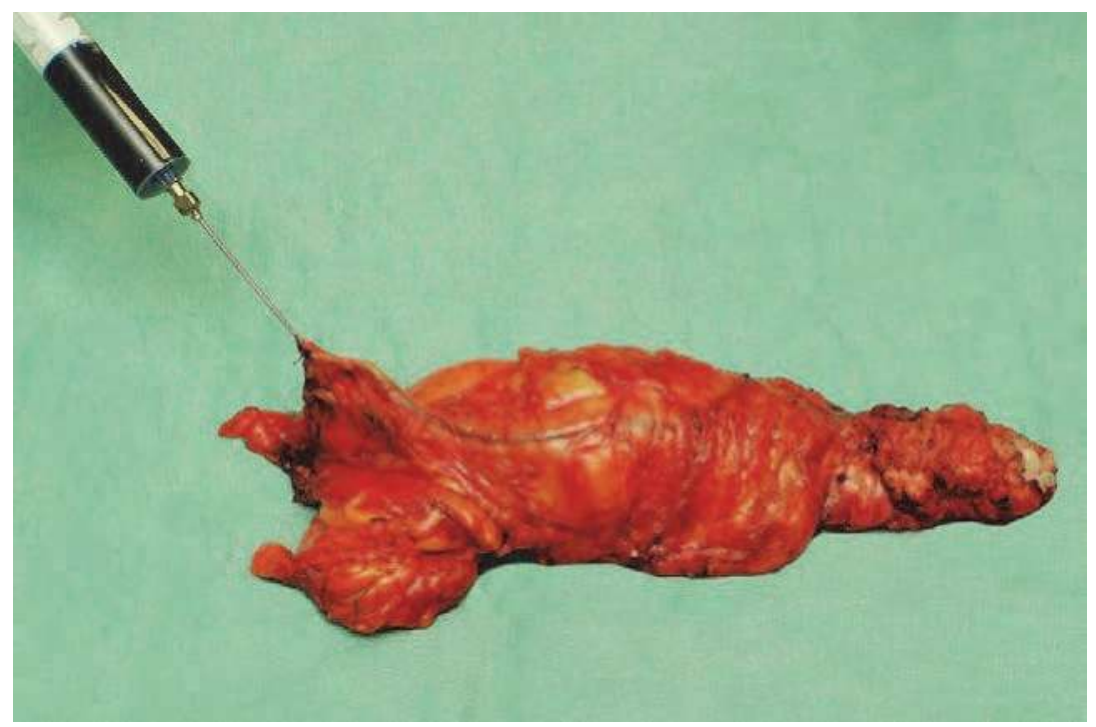

Fig. 19. Total mesorectal excision specimen 
Given these side effects, there has been an increasing interest in the locoregional treatment of early rectal cancer. Nowadays local excision for selected rectal neoplasms is an accepted treatment worldwide (Bretagnol et al., 2007). Compared to the gold standard of radical surgery, local procedures of strictly selected early rectal cancers should lead to identical oncological results and even better outcomes regarding morbidity, mortality, and quality of life.

Regardless of this trend, conventional transanal excision of rectal cancer has recently come under close scrutiny because of relatively high rates of local recurrence (Bentrem et al., 2005). In fact, scepticism has been expressed that such treatment may not be in the patient's best interest. Despite all these concerns transanal endoscopic microsurgery has become the current standard procedure for the treatment of large rectal adenomas and early low risk carcinomas with curative intent, mostly in Europe (Demartines et al., 2001, Palma et al., 2004).

As already assessed and in contrast to conventional transanal excisions using anal retractors, TEM offers an exceptionally good overview of the whole rectal cavity, allowing the precise removal of lesions not only in the lower and middle rectum but also in the upper region or even the retrorectal space, and obviates the need for major surgery.

Despite the limitations and the lack of power of clinical studies to detect differences in outcome such as survival and complication rates, TEM does appear to result in less local recurrence than other usual methods of local excision.

Furthermore, after local excision of early rectal cancer by TEM, recurrence and survival rates are comparable to those seen after major surgery, and complication rates and functional results are even superior when put into contrast with those seen after major surgery (Middleton et al., 2005).

Since the introduction of TEM in our Division of Colon \& Rectal Surgery a majority of patients with adenomas and T1 low-risk rectal cancer have been treated with local excision by this technique (Palma et al., 2004).

In 2009 we ran a single center report to evaluate the safety and oncological outcomes of TEM excision compared to radical surgery (RS) in the treatment of T1 low-risk rectal cancer. We found no statistical differences between RS and TEM in terms of local recurrence and disease free survival rates (Palma et al., 2009).

Today, various surgical techniques are still under discussion for the treatment of early rectal carcinomas. The historical gold standard procedures, such as anterior and abdominoperineal resection, show excellent results regarding local recurrence and survival rates, but are dearly paid for by a high incidence of complications and impaired quality of life (anorectal, sexual, and urinary dysfunction). Additionally, some of the patients require temporary diverting enterostomies. On the other hand, there are conventional, sphincterpreserving techniques, such as conventional transanal resection with Park's retractor (Parks, 1970), which are associated with an almost unacceptably high local recurrence rate of up to $29 \%$ (Madbouly et al., 2005).

The primary factor limiting the effectiveness of local treatment for early rectal cancer is lymph node invasion. Depths of invasion into the rectal wall, grade or degree of differentiation, vascular, lymphatic and neural invasion are independent predictors of the risk of nodal metastasis.

Since initial studies by Morson (Morson, 1985) and Hermanek (Hermanek \& Marzoli, 1994) large series of resected rectal cancers have shown that well-differentiated tumors confined to the submucosa (T1) without vascular, lymphatic or neural invasion carry a $4 \%$ risk of nodal metastasis. 
Although the reported rate of recurrence for early rectal cancers (pT1) resected by TEM is between 4 - and 14\%, follow-up and differentiation between low- and high-risk features are variable among series reported. In fact, the only published prospective study comparing TEM with radical resection for T1 low risk rectal cancer showed no statistical difference between local excision and radical resection regarding local recurrence and metastasis rate (Winde et al., 1996). These results are in accordance with our observations. We assessed two recurrences in the TEM group compared to none in the RS group. Local control is therefore undoubtedly better assessed after RS, but on the other hand it is interesting to underline that there was no statistically significant difference in overall survival and disease-free survival depending on the operation performed.

In an outstanding systematic review published recently, both comparative and case-series studies were examined to assess evidence related to the safety and efficacy of TEM compared with radical resections and conventional local excisions ((Middleton et al., 2005). Despite limited evidence the authors pointed out the unequivocal tendency of TEM to achieve better results in well-selected cases than conventional local excision, without being less effective than radical resection. The question arising is, whether TEM represents the only adequate alternative to radical resection for early rectal cancer.

The reason for the superiority of TEM over other transanal conventional techniques is the use of an optical system with 3D-view, 6-fold magnification, and human eye resolution; the creation of a stable pneumorectum, and specially designed instruments that allow fullthickness excision under excellent view conditions not only in the lower but also in the middle and upper parts of the rectum. Furthermore, full-thickness excision allows proper histological examination.

Recently we showed the ability and advantages of this technique to approach tumors located in the retrorectal space (Zoller et al., 2007).

The advantage of TEM has already been observed in the lower rate of recurrences for adenoma excision (up to $7 \%$ ) when compared to recurrence rate after transanal conventional excision (up to $27.3 \%$ ). Even for adenomas, completeness of excision is an important predictor for early recurrence. Furthermore, the literature reported a lower morbidity rate when using TEM for adenoma excision (7\% complication rate compared to $14.5 \%$ for conventional transanal surgery) (Ganai et al., 2006).

Surprisingly many publications still advocate for caution in the local excision of rectal cancer. However, these studies are questionable regarding selection criteria, use of endorectal ultrasounds preoperatively, proper "in toto" excision, and histological examination (R-Status, differentiation, and lymphovascular invasion).

In addition, some data is compromised by mainly retrospective analyses over extended time periods, and by a lack of standardized pathology reports.

The main argument explaining the high rate of local recurrences after conventional local excision could be a technically inadequate operation in which margins are insuficcient, inadequate depth of resection, or shedding and implantation of tumor cells into the surgical field (Cataldo, 2006).

Moore (Moore et al., 2008) compared 82 patients after TEM with another 89 after conventional transanal excision for rectal neoplasms. He found clear margins in 71 percent of specimens in the conventional group compared with $90 \%$ in the TEM group. Furthermore, non fragmented specimens were more likely to be found after TEM than after conventional surgery (94 vs. 65 percent). In our hands the rate of Rx and R1 after local excision was 5.88 and $2.94 \%$, respectively. 
We believe that strict patient selection criteria, together with full-thickness and margin-free excision is crucial for patient outcome. The strong correlation between incomplete tumor resection and poor outcome is widely accepted. In our experience, positive excision margins should not be regarded as a risk factor for recurrence but should be viewed as insufficient therapy requiring further treatment.

Therefore, accurate pathological examination after corkboard fixation of the specimen, and intensive, close cooperation between surgeon and pathologist cannot be overemphasized.

Although local recurrence was only observed after local excision, patients treated with TEM in our hands showed no significant differences in terms of overall survival and disease-free survival, as compared to patients who underwent RS. As local excision represents a minimally invasive technique in terms of morbidity, mortality and functional outcome, TEM should be offered as a valid option for well-selected patients with early rectal cancer.

Despite the difficulty to perform further studies in the future, comparing different methods of local excision with more radical procedures and the possible combination of neoadjuvant chemoradiation for better local and distant control even for high risk tumors (Borschitz et al., 2008), we can conclude following our published experience, that TEM should be considered as best practice to perform a local excision of well selected cases of early rectal carcinoma.

\subsection{TEM in rectal cancer after chemoradiation}

Although adjuvant or neoadjuvant chemoradiotherapy seems to improve the prognosis after local excision, the indications for any kind of therapy following local resection of rectal cancer by TEM remain controversial. In fact, local treatment of rectal cancer is limited by the impossibility of removing the potentially positive lymph nodes, supporting the concept of adjuvant radiotherapy, chemotherapy, or both to achieve local control of the lymph nodes.

Borschitz (Borschitz et al., 2008) published a review of the findings of neoadjuvant chemoradiation (nCRT) and local excision (LE) for T2-3 rectal carcinoma. He found a total of 237 patients in seven different studies available for analysis, which did in fact permit an assessment of the recurrence rates in relation to histopathological tumor response.

Patients with systemic metastases were excluded, and lymph node status was provided by only a few authors.

In most studies analysed, clinical staging before nCRT identified a T2/3 rectal carcinoma (T1 2\%; T1-2 14\%; T2 34\%; T3 50\%).

The studies reported different therapeutic concepts, tumor locations, and intervals from completion of nCRT to surgery. Nevertheless, the analysis by Borschitz identified a number of similarities among them. These were predominance of cT2-3 carcinomas and the occurrences of local recurrence (LR). Patients with response at the submucosa level (ypT1) consistently showed low LR rates of $2 \%(0 \%-6 \%)$.

Less clearly defined were the results of ypT2 findings, which ranged from $6 \%$ to $20 \% \mathrm{LR}$ rates. Clearly unfavorable were the findings in patients, whose disease did not respond to therapy (ypT3), for whom a mean LR rate of $21 \%$ was calculated. The widely divergent LR rates of ypT2 findings may be increased as a result of to nonuniform time intervals from nCRT to surgery.

The study by Borschitz confirms prior findings observed after nCRT and conventional resection. Almost no LR were reported for CR after nCRT of advanced (T3/4) tumors. Critical prognostic parameters are tumor response and tumor- free lymph nodes. LR and systemic recurrence rates ranging $0 \%$ to $23 \%$ and $8 \%$ to $22 \%$ were determined for this 
constellation. For lesions that did not respond to therapy and for persistent nodal disease, far higher LR rates ranging from $16 \%$ to $58 \%$, and metastases ranging from $35 \%$ to $58 \%$ were reported.

Neoadjuvant CRT followed by LE may represent a viable alternative to rectum extirpation in patients with low T2-3 rectal carcinoma. Despite an optimized surgical technique made available by total mesorectal excision, less favorable results were reported for tumors in the lower rectum.

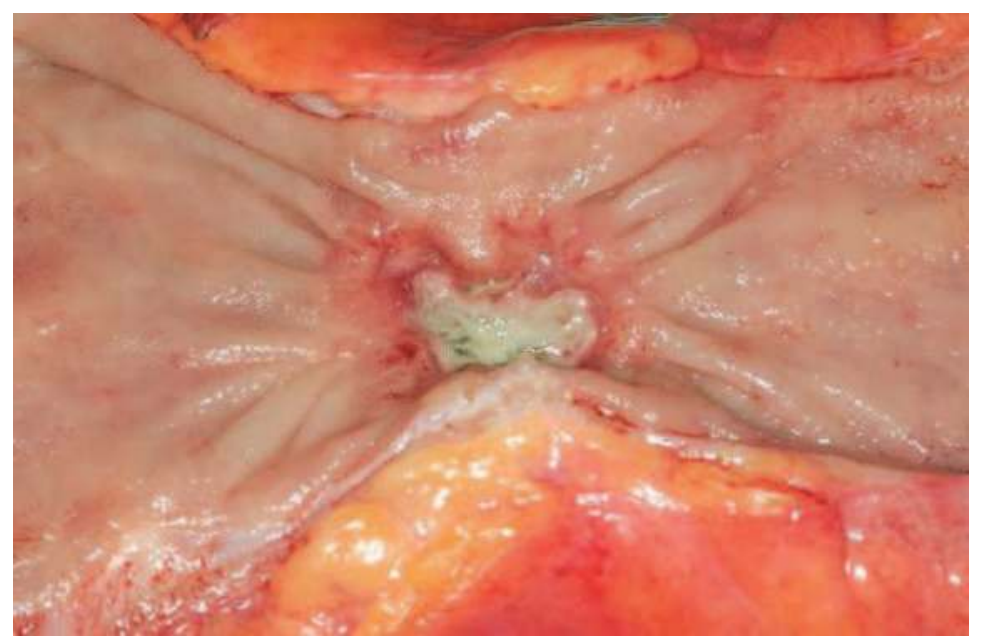

Fig. 20. Rectal cancer after neoadjuvant chemoradiation showing areas of fibrosis indicating good response

The distal mesorectum, described by Morson (Morson et al., 1963) as a "bare area," attenuates distally and is characterized by a circumferential decrease in healthy tissue surrounding the tumor, leading to a loss of tissue layers and a restricted field of view. For this region, incomplete mesorectal excision has been suggested as the cause of higher LR rates.

Local full-thickness excision may be performed as an adequate therapeutic measure for complete response (CR) after nCRT.

The described concept has been taken one step further by Habr-Gama (Habr-Gama et al., 2004) who did not find a need for subsequent surgery in patients with clinically complete responses. In her retrospective, long-term, follow-up study which so far has remained unique, she reports a LR rate of only $3 \%$ in 100 patients.

The question whether radical surgery, LE, or close-meshed follow-up alone may be appropriate in these patients, still remains largely unanswered. Furtherly it needs to be clarified, whether after nCRT with clinical confirmation of complete response, possibly remaining but vital tumor cells require surgical removal. These cells may have been damaged by irradiation and thus rendered unable to proliferate. Alternatively, some tumor cells surviving nCRT may represent resistant hypoxic clones that build the basis for development of recurrence later on.

In summary, the findings of the revision made by Borschitz support the proposition, that the indication for LE after nCRT may be extended to distal cT2-3 rectal carcinoma. The 
strongest prognostic parameter for favorable oncological outcomes is an effective tumor response without residual tumor (ypT0) or with response to at least the submucosa level (ypT1) in the excised specimen. For ypT2 tumors, the interpretation of the heterogeneous results should be performed with caution. But an extrapolation may be possible from LE alone, without nCRT. LE is not adequate in patients whose tumors exhibit no response or weak response to nCRT. These patients should be treated conventionally, that is, using radical surgery.

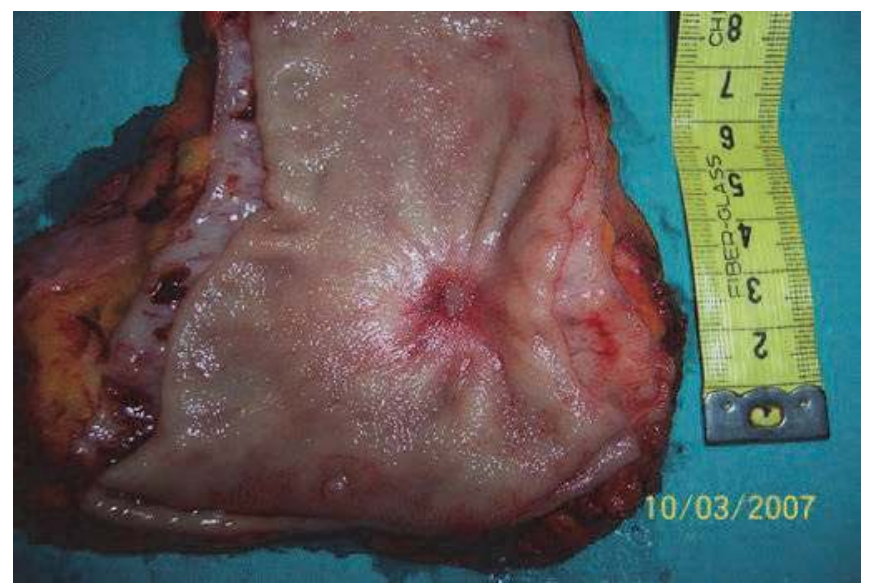

Fig. 21. Rectal cancer after neoadjuvant chemoradiation showing complete response (ypT0)

\section{Conclusion}

Transanal Endoscopic Microsurgery is a fairly new variant of transanally performed surgery of the rectal cavity, developed in Germany during the 1980's. In comparison to preceding techniques, it has largely expanded the spatial range and resolution of transanal procedures by employing state-of-the-art optics and endoscopic instruments, enabling the surgeon to reach parts of the rectum that were previously unaccessible by transanal approach.

Repassing the findings throughout the manuscript, it is evidence based to conclude that TEM currently is and prospectively will be playing an important role in the management of lower rectal neoformations.

When used in select cases of adenoma or low-grade adenocarcinoma and in accordance with the stringent indications governing more radical interventions, already in place, patients are due to benefit from less morbidity and mortality, including shorter recovery times.

Within its constraints, TEM has also shown a more favorable incidence of local recurrences compared to standard transanal surgery, while being able to parallel local recurrence rates of more extended invasive interventions, like anterior resection and abdominoperineal approaches, outlining its qualities in curative treatment of rectal cancer.

It has to be stressed, that the suitability of TEM must be determined in a meticulous preoperative staging and grading process, including MRI imaging and endorectal ultrasound, to tackle the thin red line separating availible approaches case by case.

Apart from that, TEM may also serve as a last line measure for patients unfit or unwilling to undergo laparotomy, adding to its value in managing palliative instances. 
Aditionally, in multimodal therapy schemes, including neoadjuvant chemoradiotherapy, the indication of TEM could expand, in the near future, to those patients showing a complete response.

\section{References}

Bentrem DJ, Okabe S, Wong WD, Guillem JG, Weiser MR, Temple LK. (2005) T1 adenocarcinoma of the rectum: transanal excision or radical surgery? Ann Surg; 242: 472-7.

Borschitz Th, Wachtlin D, Moehler M. (2008). Neoadjuvant Chemoradiation and Local Excision for T2-3 Rectal Cancer. Annals of Surgical Oncology, 15:712-720.

Bretagnol F, Merrie A, George B, Warren BF, Mortensen NJ. (2007) Local excision of rectal tumours by transanal endoscopic microsurgery. Br J Surg; 94: 627-33.

Buess G, Hutterer F, Theiss J, Boebel M, Isselhard W, Pichlmaier H. (1984) Das System fuer die transanale endoskopische Rectumoperation. Chirurg; 55: 677-80.

Cataldo PA. (2006) Transanal endoscopic microsurgery. Surg Clin N Am; 86: 915-25.

Demartines, N, von Flue MO, Harder FH. (2001) Transanal endoscopic microsurgical excision of rectal tumors: indications and results. World J Surg; 25: 870-5.

Ganai S, Kanumuri P, Rao RS, Alexander AI. (2006) Local recurrence after transanal endoscopic microsurgery for rectal polyps and early cancers. Ann Surg Oncol; 13: 547-56.

Habr-Gama A, Perez RO, Nadalin W, et al. (2004). Operative versus nonoperative treatment for stage 0 distal rectal cancer following chemoradiation therapy: long-term results. Ann Surg; 240:711-7.

Herman RM, Richter P, Walega P, Popiela T. (2001) Anorectal sphincter function and rectal barostat study in patients following transanal endoscopic microsurgery. Int $J$ Colorectal Dis; 16: 370-6.

Hermanek P, Marzoli GP. (1994) Lokale Therapie des Rektumkarzinoms. Verfahren in kurativer Intention. Berlin Heidelberg New York: Springer.

Lisfranc J. (1833) Memoire sur l'excision de la partie inferieure du rectum devenue carcinomateuse. Paris, Mem Ac R Méd.

Madbouly KM, Remzi FH, Erkek BA, Senagore AJ, Baeslach CM, Khandwala F. (2005) Recurrence after transanal excision of T1 rectal cancer: should we be concerned? Dis Colon Rectum; 48: 711-9.

Mentges B, Buess G, Schaefer D, Manncke K, Becker HD. (1996) Indications and results of local treatment of rectal cancer. Dis Colon Rectum; 39: 886-92.

Middleton PF, Sutherland LM, Maddern GJ. (2005) Transanal endoscopic microsurgery: a systematic review. Dis Colon Rectum; 48: 270-84.

Moore JS, Cataldo PA, Osler T, Hyman NH. (2008) Transanal endoscopic microcurgery is more effective than traditional transanal excision for resection of rectal masses. Dis Colon Rectum; 0: 1-5.

Morson BC, Vaughan EG, Bussey HJR. (1963) Pelvic recurrence after excision of rectum for carcinoma. Br Med J: 13-8.

Morson BC. (1985) Histological criteria for local excision. Br J Surg: 53-4.

Palma P, Freudenberg S, Samel S, Post S. (2004) Transanal endoscopic microsurgery: indications and results after 100 cases. Colorectal Dis; 6: 350-5. 
Palma P, Horisberger K, Joos A, Rothenhoefer S, Willeke F, Post S. (2009) Local excision of early rectal cancer: is transanal endoscopic microsurgery an alternative to radical surgery? Rev Esp Enferm Dig; 101: 172-178.

Parks AG. (1970) A technique for the removal of large villous tumours in the rectum. Proc $R$ Soc Med ; 63: 89-91.

Sakamoto GD, MacKeigan JM, Senagore AJ. (1991) Transanal excision of large rectal villous adenomas. Dis Colon Rectum; 34: 880-5.

Winde G, Nottberg H, Keller R, Schmid KW, Buente H. (1996) Surgical cure for early rectal carcinomas (T1). Transanal endoscopic microsurgery vs. anterior resection. Dis Colon Rectum; 39: 969-79.

Zoller S, Joos A, Dinter D, Back W, Horisberger K, Post S, Palma P. (2007) Retrorectal tumors: excision by transanal endoscopic microsurgery. Rev Esp Enferm Dig; 99: 547-550. 


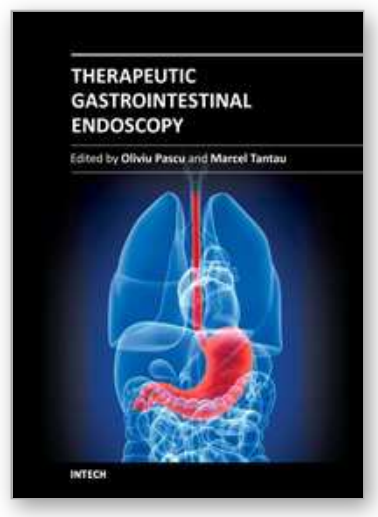

\author{
Therapeutic Gastrointestinal Endoscopy \\ Edited by Prof. Oliviu Pascu
}

ISBN 978-953-307-743-7

Hard cover, 216 pages

Publisher InTech

Published online 22, September, 2011

Published in print edition September, 2011

Endoscopy has had a big role in the development of modern gastroenterology. Modern endoscopy will certainly be more therapeutic. It started with endoscopic hemostasis and polipectomy, than beginning of the 1970 's with the advent of endoscopic sphincterotomy extended to biliopancreatic pathology and has a huge impact in this difficult pathology. Plastic stents made the first steps in endoscopic palliation of neoplastic jaundice, metallic stents, covered or uncovered are better for biliary palliation and can be used also for palliation neoplastic obstruction at different levels of the digestive tube. Resection of digestive tumors has evolved now to sub-mucosal resection, looking to have one-piece complete resection. Interventional endoscopy is now very complex and takes a lot of time for endoscopists to learn properly these techniques. This book is a very good up-to-date overview of new techniques of interventional endoscopy for those who want to learn or develop their knowledges in this field.

\title{
How to reference
}

In order to correctly reference this scholarly work, feel free to copy and paste the following:

Pablo Palma and Karoline Horisberger (2011). Transanal Endoscopic Microsurgery - State of the Art, Therapeutic Gastrointestinal Endoscopy, Prof. Oliviu Pascu (Ed.), ISBN: 978-953-307-743-7, InTech, Available from: http://www.intechopen.com/books/therapeutic-gastrointestinal-endoscopy/transanal-endoscopicmicrosurgery-state-of-the-art1

\section{INTECH}

open science | open minds

\section{InTech Europe}

University Campus STeP Ri

Slavka Krautzeka 83/A

51000 Rijeka, Croatia

Phone: +385 (51) 770447

Fax: +385 (51) 686166

www.intechopen.com

\section{InTech China}

Unit 405, Office Block, Hotel Equatorial Shanghai

No.65, Yan An Road (West), Shanghai, 200040, China 中国上海市延安西路65号上海国际贵都大饭店办公楼 405 单元

Phone: +86-21-62489820

Fax: $+86-21-62489821$ 
(C) 2011 The Author(s). Licensee IntechOpen. This chapter is distributed under the terms of the Creative Commons Attribution-NonCommercialShareAlike-3.0 License, which permits use, distribution and reproduction for non-commercial purposes, provided the original is properly cited and derivative works building on this content are distributed under the same license. 